\title{
Micro and nanostructures found on insect wings - designs for minimising adhesion and friction
}

\author{
Gregory S. Watson* and Jolanta A. Watson
}

School of Pharmacy and Molecular Sciences,

James Cook University,

Townsville, QLD 4811, Australia

Fax: +61 747816078

E-mail: greg.watson@jcu.edu.au

E-mail: jola.watson@jcu.edu.au

*Corresponding author

\section{Simon Hu and Christopher L. Brown}

School of Biomolecular and Physical Science,

Griffith University, Kessels Road,

Nathan, QLD 4111, Australia

Fax: 61737357656

E-mail: simon.hu@student.griffith.edu.au

E-mail: c.l.brown@griffith.edu.au

\section{Bronwen W. Cribb}

Centre for Microscopy and Microanalysis and

School of Integrative Biology,

The University of Queensland,

St. Lucia, QLD 4072, Australia

Fax: +61 733463993

E-mail: b.cribb@uq.edu.au

\section{Sverre Myhra}

Begbroke Science Park,

The University of Oxford,

Sandy Lane, Yarnton, OX5 1PF, UK

Fax: +44 1865848790

E-mail: sverre.myhra@materials.ox.ac.uk

\begin{abstract}
Adhesion and friction have been measured on insect wings where contamination (water and/or contaminating particles) can potentially have a detrimental effect on their flight capabilities or daily functioning. Adhesional forces as low as $2 \mathrm{nN}$ were recorded in air for particles with radii of $10-15 \mathrm{~nm}$, and $20 \mathrm{nN}$ for particles of $31 \mathrm{~mm}$ radius. The effective coefficients of friction were in the range of 0.01 to 0.10 . The low adhesion and frictional values
\end{abstract}


demonstrate that only very low out-of-plane and in-plane forces are required to remove contaminants of nanometre and micron dimensions from the cuticle membranes.

Many of the surfaces demonstrate superhydrophobic properties and will not only reduce the effects of contact with surfaces but also promote a self-cleaning function for removing foreign bodies. It has also been demonstrated that surface structures and properties can be duplicated on polymer surfaces by using the wing membrane as a 'natural template'.

Keywords: insect; wings; adhesion; friction; atomic force microscope; AFM; template; nanostructures; wetting properties.

Reference to this paper should be made as follows: Watson, G.S., Watson, J.A., Hu, S., Brown, C.L., Cribb, B.W. and Myhra, S. (2010) 'Micro and nanostructures found on insect wings - designs for minimising adhesion and friction', Int. J. Nanomanufacturing, Vol. 5, Nos. 1/2, pp.112-128.

Biographical notes: Gregory S. Watson is a Multidisciplined Research and Teaching Scientist with a Doctorate in Quantitative Nanoscience with applications and publications in the physical, chemical and biological sciences. He has 15 years of experience with scanning probe microscopy. He is currently a Senior Lecturer at James Cook University. He has authored numerous multidisciplinary scholarly publications focusing on nanoscale characterisation and surface properties including adhesion, friction and mechanical responses.

Jolanta A. Watson is a Research Scientist with a Doctorate in Material Science utilising scanning probe microscopy (SPM) with a strong background in the applications of SPM in the biological, chemical, environmental and physical sciences. She has authored numerous multidisciplinary publications focusing on micro and nanoscale properties of surfaces and their characterisation and manipulation, and applications of SPM.

Simon $\mathrm{Hu}$ is currently a confirmed, second year $\mathrm{PhD}$ student at Griffith University investigating the various functions and functional efficiencies of insect wing micro and nanostructures with the aid of scanning probe microscopy. His interests include studies of adhesive and frictional properties and interactions of natural materials with various liquid and particulate contaminants.

Christopher L. Brown is currently a Senior Lecturer in Chemistry within the School of Biomolecular and Physical Sciences at Griffith University. $\mathrm{He}$ received his $\mathrm{PhD}$ in the area of Organic Chemistry and Supramolecular Chemical Systems from the University of Sheffield (UK) in 1991. He was a Royal Society Research Fellow (1992) and the HB \& FM Gritton Research Fellow at the University of Sydney (1993-1994). Previous to taking up the position at Griffith University in 1997, he was a Senior Research Fellow at the University of Birmingham (UK) (1994-1996). He has research interests in bio-organic and medicinal chemistry, supramolecular chemical systems and surface science.

Bronwen W. Cribb is a Senior Research Fellow and Coordinator of the Education Program at the Centre for Microscopy and Microanalysis of the University of Queensland. She is an Electron Microscopist and Entomologist with interests in arthropod cuticle, its structure, composition and functional adaptations. She is also an Affiliated Lecturer with the School of Integrative Biology, The University of Queensland where she undertakes work on insect behaviour and lectures into the animal behaviour program. 
Sverre Myhra is currently a Visiting Scientist in the Department of Materials at the University of Oxford. Previously, he founded and headed an early Scanning Probe Microscopy group in Australia. He is the Author of numerous scholarly papers and chapters in the area of materials science and technology focusing on surface and interface analysis, with a recent emphasis on the applications of scanning probe microscopy. He received his $\mathrm{PhD}$ (1968) in Physics from the University of Utah, Salt Lake City.

\section{Introduction}

The promise of controlling the adhesion between surfaces at various length scales, together with an advanced understanding of the processes involved, will ultimately lead to the next generation of contamination resistant and self-cleaning surfaces (Blossey, 2003). Adhesion control between surfaces, whether as solid-solid or solid-liquid contacts, affects all aspects of life from the need to keep surfaces clean, to the state-of-the-art of droplet-based micro-fluidics systems (Blossey, 2003; Lehto et al., 1999). The control of adhesion between contacts is critical in a number of industrial applications and more importantly for predicted future technologies. Progress in nanotechnology and in particular, nanoelectromechanical systems has prompted studies of new materials and importantly new structure designs with requirements of low adhesion, friction and wettability. The contact area and wettability will affect the adhesion, friction and wear, and may inhibit, possibly prohibit, the functionalities of micromechanical and nano-sized devices as well as the impact on their ultimate life expectancy (Abdelsalam et al., 2005; Ando and Ino, 1998; Burton and Bhushan, 2005; Mastrangelo, 1997). The Holy Grail in regards to adhesion would be the ability to fabricate surfaces at two extremes - a surface that adheres to anything and a surface that nothing will adhere to.

Many naturally occurring nanostructures have functional efficiencies, which are superior to man-made technologies. One of the most noteworthy nanocomposite materials is the insect cuticle (Vincent and Wegst, 2004). Recently, micro- and nanostructures found on insect cuticle have been shown to exhibit a range of impressive and remarkable properties such as superhydrophobicity, directed wetting and ultra low adhesion (Cong et al., 2004; Gorb et al., 2000; Parker and Lawrence, 2001; Watson et al., 2008).

The mechanisms and functional efficiency of nanostructures identified on a variety of insects has as yet not received a great deal of attention. One of the major obstacles for a greater understanding of these structures has been the inability to undertake surface and interface characterisation on the nanoscale. The development of instrumentation and techniques such as the atomic force microscope (AFM), and the latest generation of imaging and analytical electron-optical techniques has given the scientific community new tools with which to visualise and analyse on the nano- and meso-scale the structure and properties of surfaces and interfaces.

A study and seminal work by Wagner et al. (1996) showed that there was a correlation between contaminability, wettability and the wing area of many insects. They exposed insect specimens to a fine silica dust and fogging conditions showed that large winged insects such as butterflies exhibited contamination resistant surfaces and had very unwettable wings, while smaller winged insects (e.g., flies) showed the opposite trend. Additional weight due to contamination (water and/or contaminating particles) can 
potentially have a detrimental effect on the flight capabilities of large wing insects (Wagner et al., 1996). Insects with a very high wing surface area-to-body mass (SA/BM) will have an even greater susceptibility to these effects. In this study, we have measured the wetting properties and micro/nano adhesion/friction of a number of insect species with large wings and/or a high SA/BM value and/or a close association with water in their life history.

\section{Experimental section}

\subsection{Atomic force microscopy}

The investigations were carried out on two multi-technique/multi-mode instruments: a ThermoMicroscope TMX-2000 Explorer/Discoverer and a JEOL JSPM-4200. The two instruments have broadly comparable capabilities and are both based on detection of tip-to-surface forces through the monitoring of the optical deflection of a laser beam incident on a force-sensing/imposing lever. The analyses were carried out under air-ambient conditions (temperature of $20-25^{\circ} \mathrm{C}$ and $60-75 \% \mathrm{RH}$ ). The probe consists of a lever and an integral tip. 'Beam-shaped' probes (NT-MDT Ultrasharp) were used throughout the work. Typical parameters, as reported by the manufacturer, were: normal force constant, $k_{N}$, of $0.03-4.5 \mathrm{~N} / \mathrm{m}$; conical tip shape with cone angle $<20^{\circ}$, radius of curvature of the tip $<10 \mathrm{~nm}$; and tip height of $17.5 \mu \mathrm{m}$. The actual normal force constant was determined by accepted methods (Cleveland et al., 1993), and the torsional force constant was calculated from the expression for a long and thin lever (Gibson et al., 1997a, 1997b).

Topographical imaging was carried out at constant force in contact mode, with a lever-imposed normal force in the range $5-15 \mathrm{nN}$. The scanning rate in the fast-scan direction was ca. $3 \mathrm{~Hz}$, and a typical image was composed of $500 \times 500$ pixels. Insect wings (dried samples) were surgically separated by scalpel. The forewings were cut into smaller sections $\left(3 \times 5 \mathrm{~mm}^{2}\right)$ and attached by adhesive tape, or by an epoxy resin, to AFM-mounted stubs.

\subsection{Force distance adhesion data}

Force versus distance (f-d) analysis was used to obtain adhesion data. The tip is held stationary at an $x-y$ (sample plane) location and is ramped along the $z$-axis, first in the direction of approach and contact with the surface, and then in the reverse direction. F-d curves were acquired at rates of translation in the $z$-direction in the range $2-10 \mu \mathrm{m} \mathrm{s}^{-1}$. Each f-d curve consisted of 300-600 data points. The attachment procedure for $\mathrm{SiO}_{2}$ spheres (corpuscular) to AFM tipless cantilevers has been described in the literature (Watson et al., 2003, 2004). Fifty measurements per particle, microsphere or nano tip-substrate size combination were acquired. Adhesion was measured under the conditions of the two surfaces coming into contact with no applied loading force.

\subsection{Frictional force data}

Frictional forces were measured using friction loops. Analysis was carried out by monitoring the torsional deformation of the lever during forward and reverse line scans $20 \mu \mathrm{m}$ in length. The normal force and linear scan speed was $5 \mathrm{~Hz}$. 
Friction measurements were carried out at the adhesion force loading (i.e., at a loading force, which represented the adhesion force of contact between the wing membrane and the spherical particle).

\subsection{Scanning electron microscopy}

In the case of scanning electron microscope (SEM) imaging, a square of dried wing tissue (approx. $3 \times 5 \mathrm{~mm}^{2}$ ) was excised and mounted on an aluminium pin-type stub with carbon-impregnated double-sided adhesive, then sputter coated with 7-10 nm of platinum, before being imaged using a JEOL 6300 field emission SEM at $8 \mathrm{kV}$.

\subsection{Contact angle measurements}

Where possible, in order to eliminate effects of the vein structure on the wing membrane, water droplets were placed on regions sufficiently large to accommodate the droplet footprint. Droplets of $10 \mu \mathrm{l}$ Milli-Q water were applied to the wing membranes (if possible, near the dorsal cell region between veins $\mathrm{CuA}$ and $\mathrm{M}$ ), which was attached to a glass substrate with double-sided adhesive tape. Smaller sized droplets were difficult to place on the membrane surfaces due to the adhesion between the water droplet and the syringe needle being stronger than the force of gravity and adhesion of the cuticle surface. In the case of the lacewing, a smaller droplet size was used by spraying a fine water mist onto the membrane. This was carried out in order to remove the effects of the fine hairs (macrotrichia) along the vein regions interacting with the water droplet as water droplets were 'levitated' above the cuticle membrane surface. The static contact angles (CAs) were measured with a horizontal microscope with digital capturing of the images for precise measurements (with ten measurements per droplet). The measurements were taken at ambient conditions of $21^{\circ} \mathrm{C}$ and $\mathrm{RH}$ of $60-75 \%$.

\subsection{Replication process}

Negative replicas were produced by laying the whole wings on liquid Epon araldite resin held in a silicone rubber mould. The resin was polymerised at $60^{\circ} \mathrm{C}$ for three days. After cooling, the wing tissue was pulled away from the resin leaving an impression that was used to produce a positive cast.

The casts were then formed by the application of PolyDiMethylSiloxane (PDMS) $\left(\right.$ Sylgard $\left.^{\circledR}-184\right)$. PDMS was supplied by Dow Corning as a two-part silicone elastomer. The base and curing agent were mixed at a 10:1 weight ratio, poured over the patterned resin and cured in an oven at $60^{\circ} \mathrm{C}$ for a sufficient amount of time to fully cure the polymer.

\section{Results and discussion}

\subsection{Topographical characterisation of insect wing cuticle}

The surfaces of the transparent cicada wing membranes of Psaltoda claripennis and Cicadetta oldfieldi are covered with a number of periodic structures. The structures are shown in topographical SEM images (top and cross-sectional views) in Figures 1(a) to 
1(d), respectively, with the relevant geometrical parameters listed in Table 1. The arrays consist of hexagonally-packed spherically-capped conical protuberances with a spacing and height of ca. $200 \mathrm{~nm}$ and radius of curvature of $35-55 \mathrm{~nm}$ at the apex as shown in the AFM image and line profile in Figures 1(e) and 1(f), respectively. Similar features have been found on the wings of a number of other cicada species including Tamasa tristigma, Macrotristria angularis and Thopha saccata (Watson et al., 2007). The features are present on all areas of the dorsal and ventral wing membrane sections. A previous study has demonstrated the functional effectiveness of similar structures as an antireflective surface, which presumably helps to camouflage the insect from predators (Watson et al., 2008). The surfaces also demonstrated low adhesion with hydrophilic particles (Watson et al., 2008). The multi-functional nature of the structures is typical of the cuticle found on many insect species.

Three other cicada species [Gudanga sp. nr adamsi (black cicada), Gaeana cheni and Tosena sybilla] were examined, which had coloured, non-transparent wing regions as opposed to the species discussed above, which all have transparent fore and hind wings. Their respective top and cross-sectional views are shown in topographical SEM images in Figures 2(a) to 2(f). The cuticular structures varied significantly between the three species and ranged from a height of $200 \mathrm{~nm}$ to over $1.5 \mu \mathrm{m}$. Interestingly, transparent regions on the black cicada wing membrane (hind wing) showed the same well-ordered structure size, shape and periodicity as found on other cicada with completely transparent wings. The non-transparent coloured part of the forewing (black in colour) possessed less ordered surfaces with individual structures almost one order of magnitude larger in height and (maximum) width. This provides strong evidence for specific dimensional structure size for specific functionality on selected regions of the wings. Regions of the wing where the antireflection property is required have the necessary structure dimensions [less than the wavelength of light (Watson and Watson, 2004; Watson et al., 2008)] while other coloured regions are not restricted by this wavelength condition. Slight structure size and shape differences can be seen on two different coloured regions on the forewing of Gaeana cheni, as shown in Figures 2(c) to 2(f). SEM images in Figures 2(c) and 2(d) show structures on a yellow coloured region on the forewing whereas Figures 2(e) and 2(f) are structures on brown coloured regions on the forewing of the cicada showing a height and width difference of ca. $110 \mathrm{~nm}$ and ca. $300 \mathrm{~nm}$, respectively (see also Table 1). Figures 2(g) and 2(h) show spherically-capped cones on the surface of the Tosena sybilla cicada forewing.

The dragonfly (Rhyothemis phyllis chloe) and planthopper (Desudaba psittacus) presented comparable surface topographies with rod-like structures forming a layer of structured matting as shown in Figures 3(a) and 3(b), respectively. These structures are similar to those found on damselflies (Gorb et al., 2000). In that study, the authors suggested a number of possible functions for the wax covering including intra/inter-specific communication based on ultraviolet light reflection of the layer. The covering was also suggested to protect against the insect when in contact with water (Gorb et al., 2000).

The moth (Prasinocyma albicosta) topography showed scales with a typical overlaying tile type arrangement as found on many butterfly species (Cong et al., 2004). These scales exhibited micron [SEM image in Figure 4(a)] and submicron structure in the form of longitudinal and lateral ridges as seen in the cross-sectional SEM image of a single scale in Figure 4(b). A number of functional properties have been attributed to scales on butterflies including camouflage display, signalling and possibly 
thermo-regulation control (Wong et al., 1997). The scales are also hydrophobic and can detach as an aid for protection against highly adhesive surfaces (e.g., spider web).

Figure 1 Topographical SEM images of the top and cross-sectional layer of, (a, b) Psaltoda claripennis (c, d) Cicadetta oldfieldi cicada wing membranes, respectively, revealing an array of periodic structures (e, f) AFM topographical image and line profile of the arrays
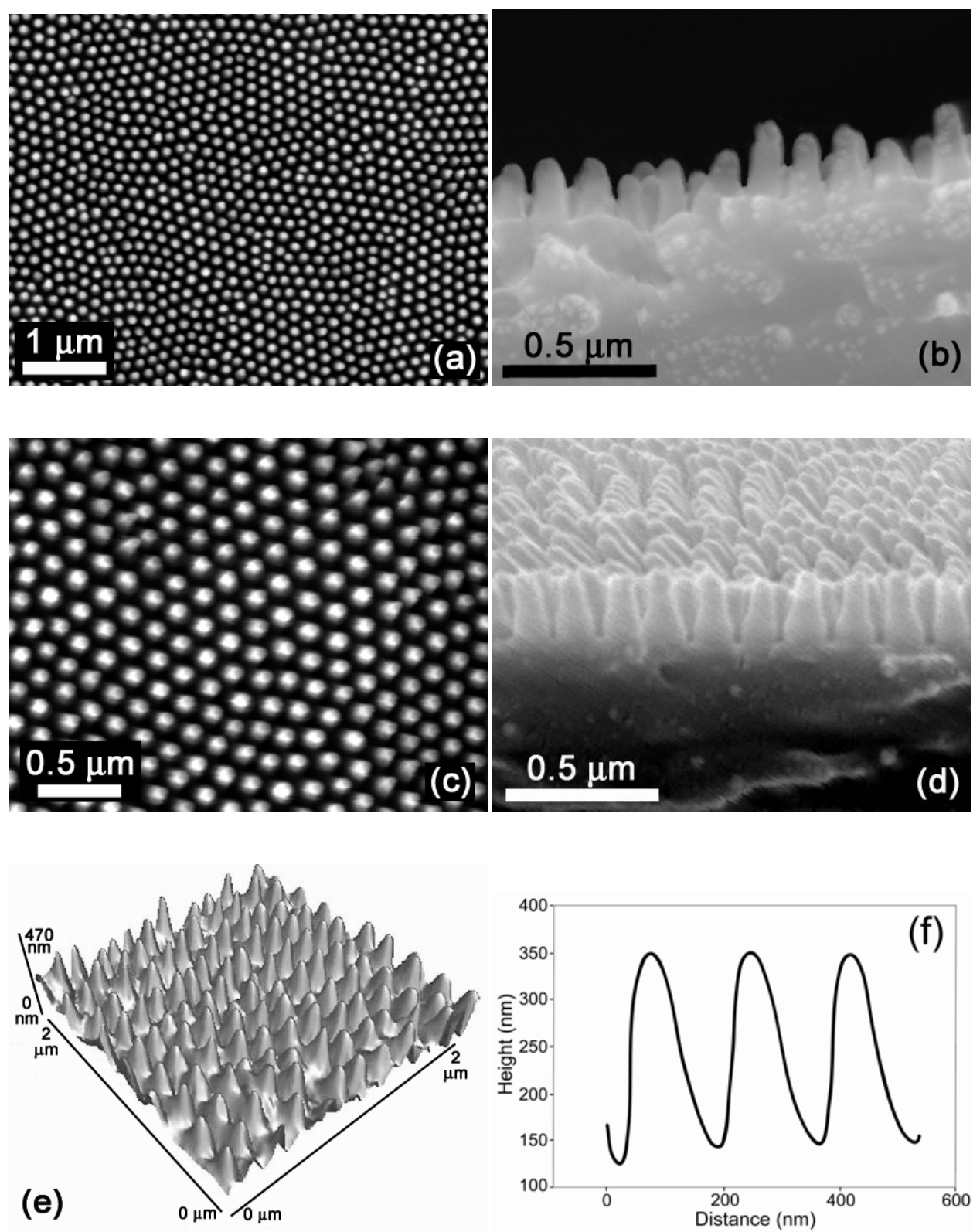
Table 1 Geometrical parameters of insect species investigated in this study

\begin{tabular}{|c|c|c|c|c|c|}
\hline Type/species & Height & $\begin{array}{c}\text { Structure } \\
\text { density }\end{array}$ & $\begin{array}{l}\text { Structure } \\
\text { width }\end{array}$ & $\begin{array}{c}\text { Structure } \\
\text { spacing/ } \\
\text { periodicity }\end{array}$ & Shape \\
\hline $\begin{array}{l}\text { Cicada } \\
\text { Psaltoda } \\
\text { claripennis }\end{array}$ & $\begin{array}{c}200 \mathrm{~nm} ; \\
\mathrm{SD} 30 \mathrm{~nm}\end{array}$ & $37 / \mu \mathrm{m}^{2}$ & $\begin{array}{l}90 \mathrm{~nm} \\
20 \mathrm{~nm}\end{array}$ & $170 \mathrm{~nm}$ & $\begin{array}{c}\text { Spherically } \\
\text { capped conical }\end{array}$ \\
\hline $\begin{array}{l}\text { Cicada } \\
\text { Cicadetta } \\
\text { oldfieldi }\end{array}$ & $\begin{array}{c}200 \mathrm{~nm} \\
\mathrm{SD} 28 \mathrm{~nm}\end{array}$ & $42 / \mu \mathrm{m}^{2}$ & $\begin{array}{c}80 \mathrm{~nm} \\
\text { SD } 15 \mathrm{~nm}\end{array}$ & $200 \mathrm{~nm}$ & $\begin{array}{c}\text { Spherically } \\
\text { capped conical }\end{array}$ \\
\hline $\begin{array}{l}\text { Black cicada } \\
\text { Gudanga sp. } \\
\text { Nr adamsi }\end{array}$ & $\begin{array}{c}\text { Forewing - } \\
1.5 \mu \mathrm{m} ; \\
\text { SD } 0.19\end{array}$ & $0.24 / \mu \mathrm{m}^{2}$ & $\begin{array}{l}680 \mathrm{~nm} \\
70 \mathrm{~nm}\end{array}$ & $2.1 \mu \mathrm{m}$ & $\begin{array}{c}\text { Diamond-like } \\
\text { shape }\end{array}$ \\
\hline \multirow[t]{2}{*}{$\begin{array}{l}\text { Cicada } \\
\text { Gaeana } \\
\text { cheni }\end{array}$} & $\begin{array}{l}\text { Yellow region: } \\
680 \mathrm{~nm} ; \\
\text { SD } 125 \mathrm{~nm}\end{array}$ & $0.22 / \mu \mathrm{m}^{2}$ & $\begin{array}{c}745 \mathrm{~nm} \\
\text { SD } 170 \mathrm{~nm}\end{array}$ & $2.1 \mu \mathrm{m}$ & $\begin{array}{c}\text { Spherically } \\
\text { capped pillars }\end{array}$ \\
\hline & $\begin{array}{l}\text { Brown region: } \\
790 \mathrm{~nm} \text {; } \\
\text { SD } 240 \mathrm{~nm}\end{array}$ & $0.35 / \mu \mathrm{m}^{2}$ & $\begin{array}{c}1050 \mathrm{~nm} \\
\text { SD } 160 \mathrm{~nm}\end{array}$ & $1.7 \mu \mathrm{m}$ & $\begin{array}{c}\text { Spherically } \\
\text { capped pillars }\end{array}$ \\
\hline $\begin{array}{l}\text { Cicada } \\
\text { Tosena } \\
\text { sybilla }\end{array}$ & $\begin{array}{c}1880 \mathrm{~nm} ; \\
\text { SD } 460 \mathrm{~nm}\end{array}$ & $0.32 / \mu \mathrm{m}^{2}$ & $\begin{array}{c}760 \mathrm{~nm} \\
\text { SD } 130 \mathrm{~nm}\end{array}$ & $1.7 \mu \mathrm{m}$ & $\begin{array}{l}\text { Spherically } \\
\text { capped cones }\end{array}$ \\
\hline $\begin{array}{l}\text { Dragonfly } \\
\text { Rhyothemis } \\
\text { phyllis chloe }\end{array}$ & $\begin{array}{c}350 \mathrm{~nm} ; \\
\text { SD } 35 \mathrm{~nm}\end{array}$ & $43 / \mu \mathrm{m}^{2}$ & $\begin{array}{l}80 \mathrm{~nm} \\
10 \mathrm{~nm}\end{array}$ & $150 \mathrm{~nm}$ & Rods \\
\hline $\begin{array}{l}\text { Planthopper } \\
\text { Desudaba } \\
\text { psittacus }\end{array}$ & $\begin{array}{l}400 \mathrm{~nm} ; \\
\text { SD } 79 \mathrm{~nm}\end{array}$ & $52 / \mu \mathrm{m}^{2}$ & $\begin{array}{l}60 \mathrm{~nm} \\
10 \mathrm{~nm}\end{array}$ & $150 \mathrm{~nm}$ & Rods \\
\hline $\begin{array}{l}\text { Moth } \\
\text { Prasinocyma } \\
\text { albicosta }\end{array}$ & $\begin{array}{l}\text { Valley/peak } \\
\text { dist. } 500 \mathrm{~nm} \text {; } \\
\text { SD } 100 \mathrm{~nm}\end{array}$ & - & $\begin{array}{c}120 \mathrm{~nm} \\
\mathrm{SD} 15 \mathrm{~nm}\end{array}$ & $\begin{array}{c}\text { Longitudinal } \\
\text { ridge spacing - } \\
1500 \mathrm{~nm} \\
\text { Ridge width: } \\
\text { thin }-120 \mathrm{~nm} \text {; } \\
\text { thick }-390 \mathrm{~nm}\end{array}$ & $\begin{array}{c}\text { Scales, } \\
\text { longitudinal } \\
\text { ridges, lateral } \\
\text { crossbeams }\end{array}$ \\
\hline $\begin{array}{l}\text { Lacewing } \\
\text { Glenoleon } \\
\text { pulchellus }\end{array}$ & $\begin{array}{c}950 \mathrm{~nm} \\
\text { SD } 100 \mathrm{~nm}\end{array}$ & - & $\begin{array}{c}80 \mathrm{~nm} \\
\text { SD } 50 \mathrm{~nm}\end{array}$ & - & $\begin{array}{l}\text { Interconnected } \\
\text { netting } \\
\text { composed of } \\
\text { ridges }\end{array}$ \\
\hline
\end{tabular}

The SEM image of the lacewing (Glenoleon pulchellus) showed interconnected ridges forming dense netting on the cuticle surface (Figure 5). The vein regions were characterised with an array of macrotrichia. These fine hairs add a secondary layer of protection against surfaces with which the insect may come into contact. The lacewing surface has been previously studied, whereby the wing was exposed to a fine dust of silica particles under fogging conditions and was shown to exhibit a high degree of non-contaminability (Wagner et al., 1996). 
Figure 2 Topographical SEM images of the top and cross-sectional regions of, (a, b) Gudanga $s p$. $n$ r adamsi (black cicada) (c, d) yellow coloured region (e, f) brown regions on the Gaeana cheni forewing $(\mathrm{g}, \mathrm{h})$ Tosena sybilla
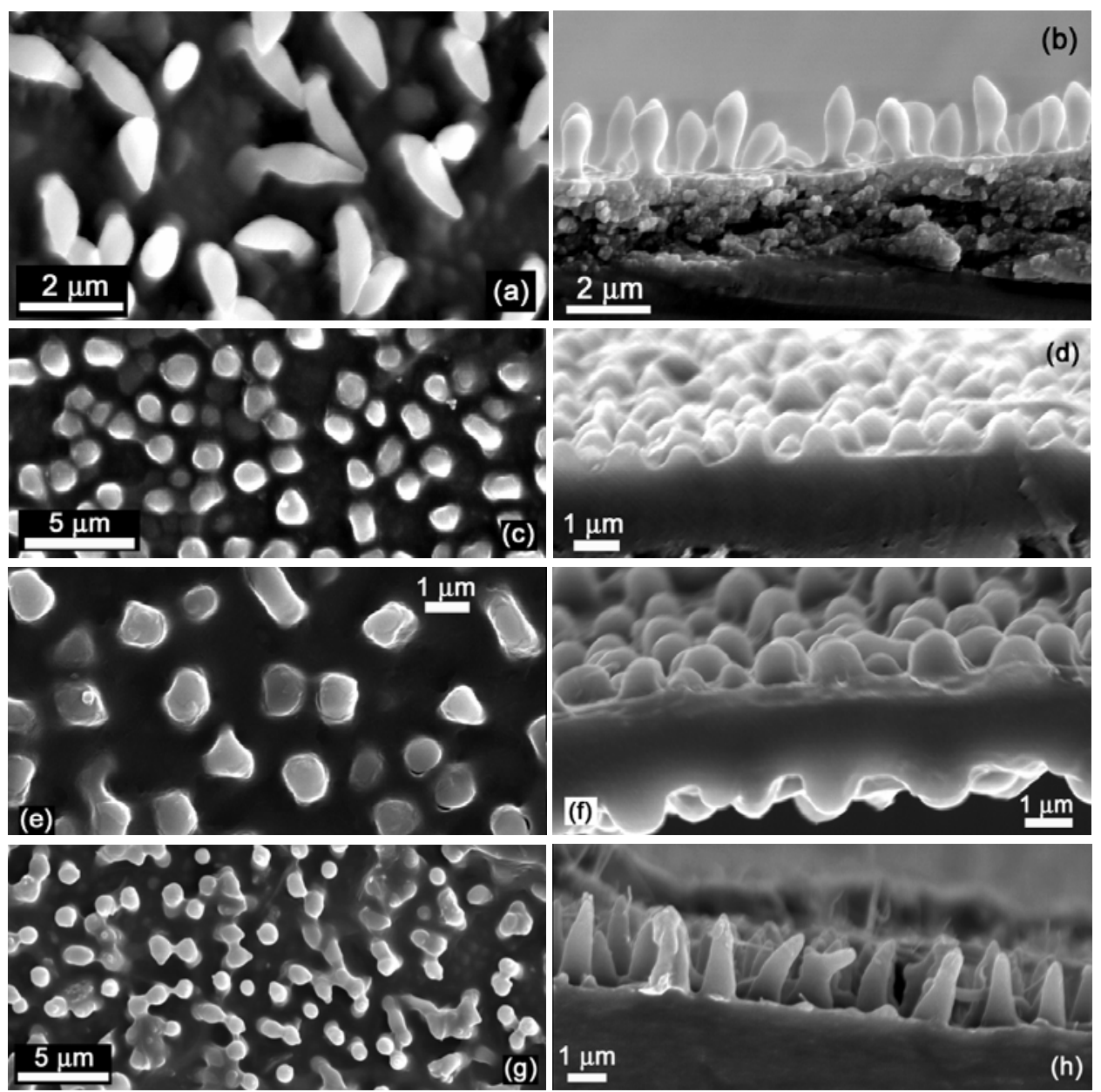

Figure 3 SEM images of (a) dragonfly (Rhyothemis phyllis chloe) and (b) planthopper (Desudaba psittacus) forewings revealing rod-like structures forming a layer of structured matting

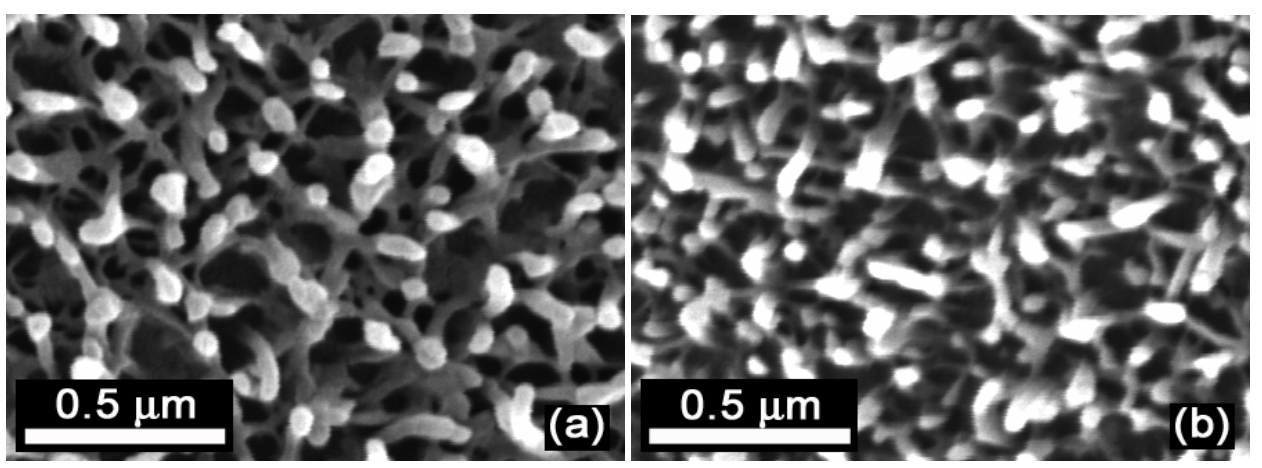


Figure 4 Topographical SEM images of a moth wing scale (Prasinocyma albicosta)
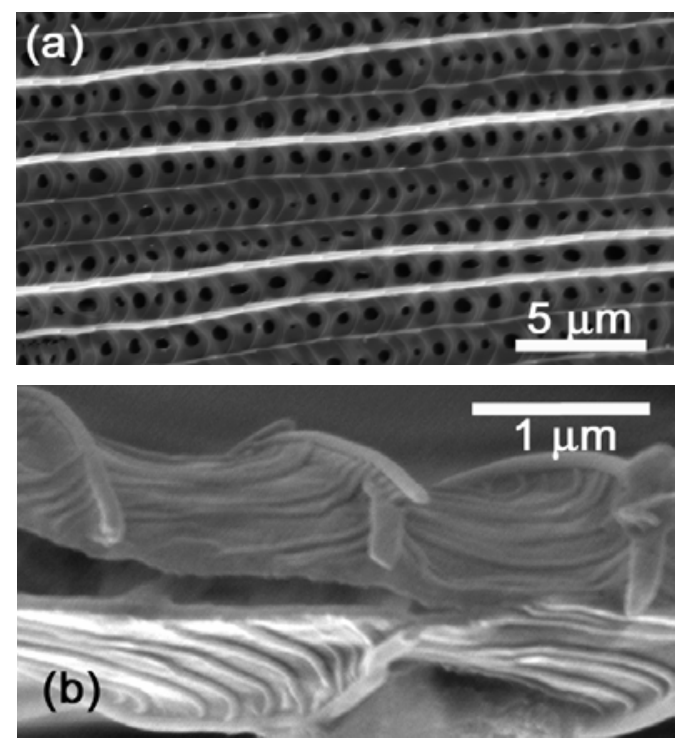

Figure 5 SEM image of Glenoleon pulchellus

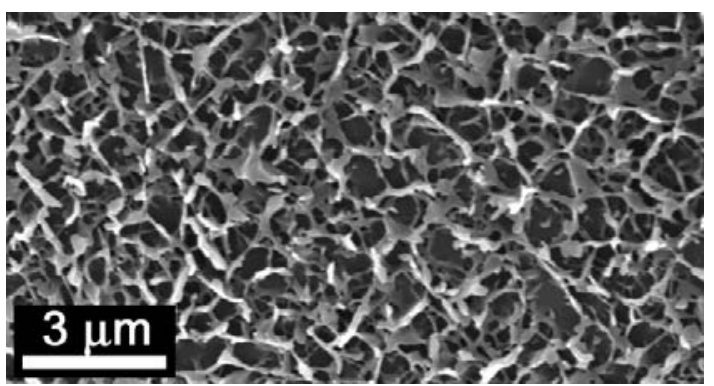

\subsection{Wettability}

Many insects already have chemistries, which result in CAs, which are near the upper limit for what can be achieved on flat surfaces. Thus, topographical architectures resulting in increased roughness as shown in this study are one way to improve on an already low energy surface. The non-wetting surfaces offer survival value to insects as they afford resistance to wetting by rain and other water surfaces they may encounter.

The wettability (contact angle (CA)) of the insect wing cuticles in this study is shown in Figure 6(a) (right axis). The membranes represent superhydrophobic surfaces where static CAs are close to or above $150^{\circ}$. A typical example is shown in Figure 6(b) (cicada with structure height and periodicity of $200 \mathrm{~nm}$ ) where it is evident from the image that the water droplet gains negligible energy through absorption to compensate for any enlargement of its surface area. For comparison, a flat PDMS sample, a well-known hydrophobic surface [with a measured CA of ca. 101-105 ${ }^{\circ}$, in good agreement with values reported in the literature (Rolland et al., 2004)] highlights the hydrophobic character of the wing membranes [Figure 6(c)]. 
Figure 6 (a) Wettability (CA) measurements (right axis) and adhesional values (left axis) between a silicon tip and $31 \mu \mathrm{m}$ silica sphere interacting with a silicon oxide surface and the various natural membranes $(b, c) C A s$ on an insect wing membrane and a flat PDMS surface
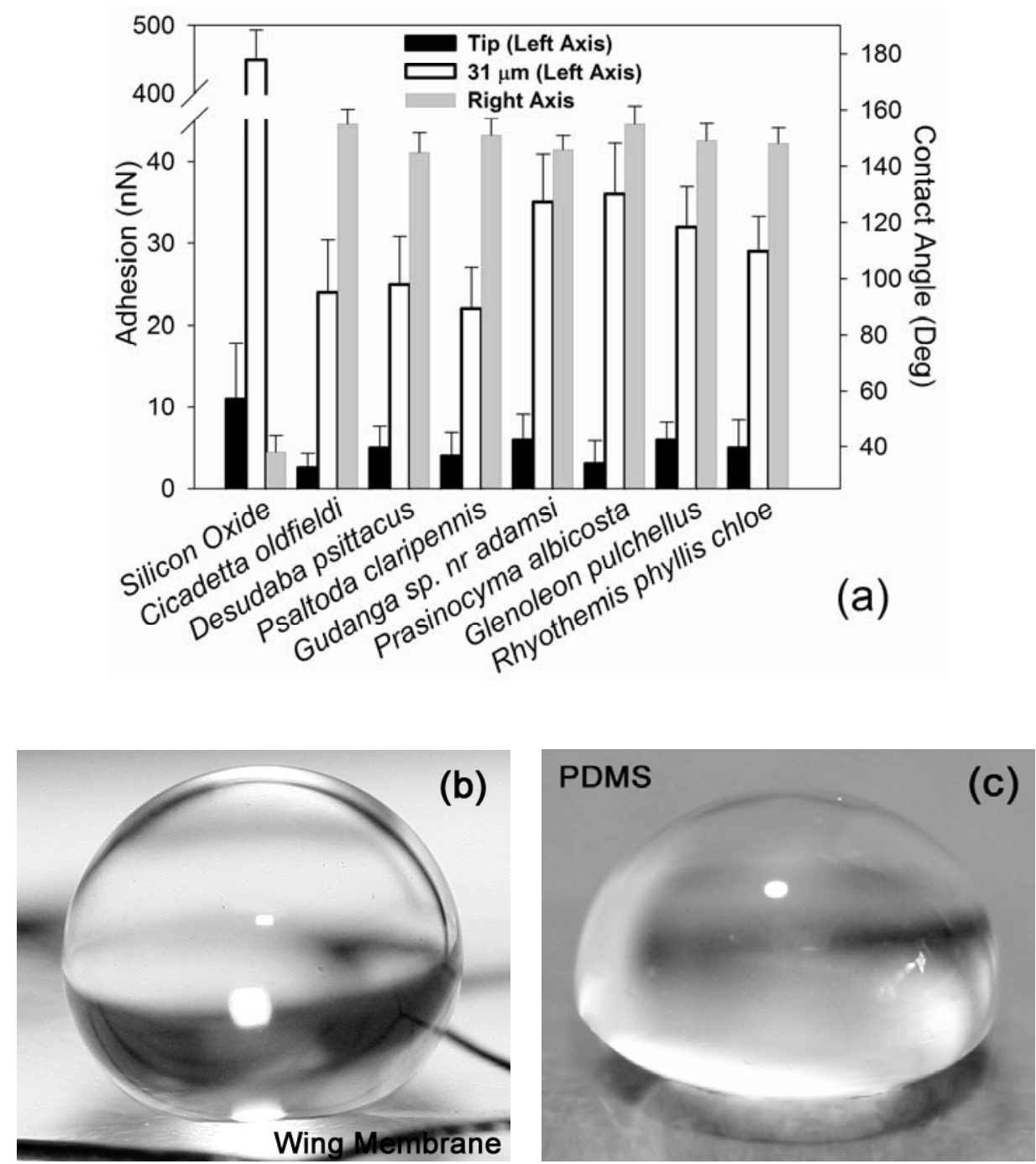

There are a number of theories to express the superhydrophobic condition all of which have certain assumptions and limitations (Cassie and Baxter, 1944; Gao and McCarthy, 2007; Wenzel, 1936). Cassie and Baxter express the superhydrophobic state in terms of a number of interfaces, a liquid-air interface with the ambient environment surrounding the droplet and a surface under the droplet involving solid-air, solid-liquid and liquid-air interfaces. Equation (1) shows the CA formed with a rough surface.

$$
\cos \theta_{C}=R_{f} f_{S L} \cos \theta+f_{S L}-1
$$


where $R_{f}$ is the roughness factor defined by the solid-liquid area to its projection on a flat plane (the roughness factor of the wetted area), $f_{S L}$ is the fraction of the solid/water interface (the area fraction of the projected wet area), and $\theta$ represents the CA which would occur on a smooth surface with the identical chemistry and can be expressed by the Young's relation $\theta=\left(\gamma_{S V}-\gamma_{S L}\right) / \gamma_{L V}$ where the $\gamma_{i j}$ terms correspond to the solid-vapour, solid-liquid and liquid-vapour interfacial energies/tensions, respectively. Equation (1) necessitates the surface to have the required roughness to trap air in topographically favoured regions such as troughs and surface depressions. Thus, topographies, which increase the air-water interface and minimise the solid-liquid contact area will lead to higher CAs.

All the insect species demonstrate specialised topographies for minimising the solid-liquid contact area and maximising the liquid-air contact. The non-transparent cicada wing cuticles of Gudanga $s p$. for example present structures, which satisfy a number of the above contact conditions. The diamond-like shape demonstrates design features for material minimisation with reduced weight and lowers the solid-liquid contact area while at the same time allowing a larger pocket/volume of air to be trapped beneath the water droplet. The spacing between individual structures as seen in Figures 2(a) to 2(h) are generally less than $5 \mu \mathrm{m}$ and this suggests that this may be near a critical distance for structures of these heights (several $\mu \mathrm{m}$ ) interacting with water. The membrane must be resistant to water under a variety of conditions so as not to invade or make contact with the underlying surface between asperities increasing the solid-liquid contact or promoting a transition to the fully wetted state. The Cassie-Baxter model can be used to describe an array of hemispherical-top protrusions (a close approximation to the structures shown in Figures 2(c) to 2(f) for the Gaeana cheni cicada) from equation (2)

$$
\cos \theta_{C}=-1+\phi_{B}\left(\cos \theta_{Y}+1\right)^{2}
$$

where $\phi_{B}$ is the ratio of the basal area of the protrusion over the total area, $d$ is the diameter of the base of the protrusions, $h$ is the structure height, and $l$ is the centre-to-centre pitch (nearest-neighbour spacing for an ordered array). $\theta_{Y}$ is the ideal CA of water on a smooth surface of identical chemistry $\left[\theta_{Y} \sim 105^{\circ}\right.$ in the present case e.g., (Watson et al., 2008)]. The predicted CA for the cicada membrane is $\sim 148^{\circ}$. This value correlates well with the experimentally determined value shown in Figure 8. The cicada species with transparent wing membranes are forced to compromise the geometrical structure parameters due to the antireflection constraint as mentioned above. Even so, the membrane still manages to achieve superhydrophobic CAs. A recent study of fabricated superhydrophobic nanostructures with comparative spacing and height to the cicada arrays reported measured values of CA similar to our results (Martines et al., 2005).

The dragonfly, leafhopper and lacewing present denser regions of smaller asperities on the surface, which will increase the air pocket volume by the three-dimensional 'undergrowth' of surface matting on the membrane. The moth topography has an anisotropic hierarchy of roughness with the scales and ridges minimising contact with water bodies.

Polymer replicas have been suggested and used to enhance hydrophobicity tailored by insect nanostructures by a templating procedure (Watson and Watson, 2004; Watson et al., 2008). The insect cuticle structures in the present study were replicated using this 
technique. All of the replicated samples showed increased CAs approaching or equal to the original natural templates. The similar measurements after replication are not surprising as PDMS has a CA comparable to that of the hydrophobic chemistry of many insect cuticles (Gao and Jiang, 2004; Tong et al., 2005; Watson et al., 2007).

A typical outcome, as seen in Figures 7(a) and 7(b), shows a droplet in contact with the insect forewing (Desudaba psittacus) and PDMS replica.

The PDMS replicas of the two different cicada wings, Cicadetta oldfieldi and Gaeana cheni, and a lacewing membrane (Glenolean pulchellus) are shown in Figure 8(c). The figure also illustrates the increased hydrophobicity when roughness is introduced to the polymer surface. The area of the fabricated replica is restricted to the wing dimensions and includes the imprints of the vein structures.

Figure 7 CA measurement on a, (a) planthopper forewing (b) a PDMS replica of the region with a $10 \mu$ droplet
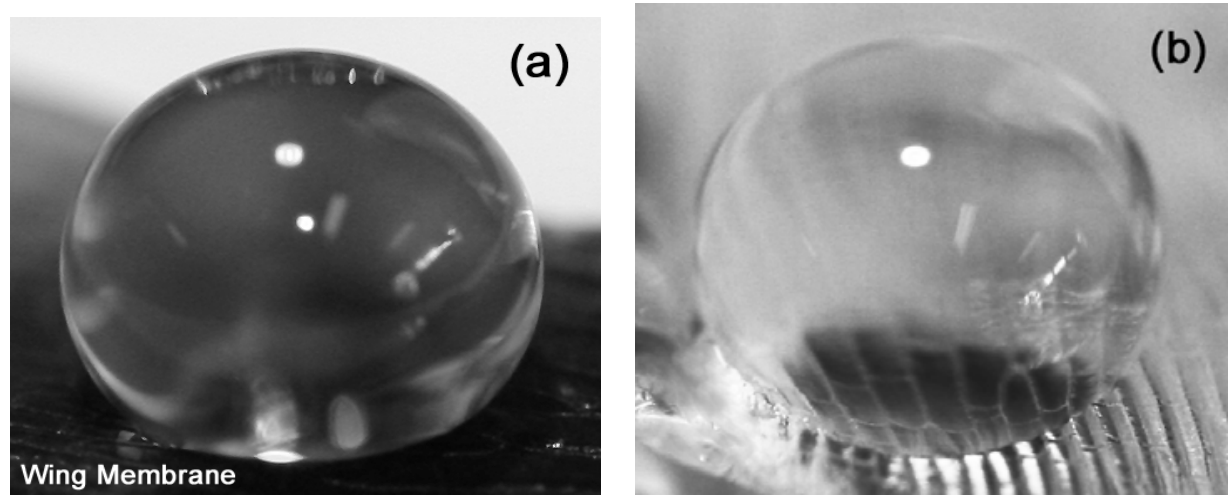

Figure $810 \mu \mathrm{l}$ water drops on PDMS replicas of Cicadetta oldfieldi, Gaeana cheni and Glenolean pulchellus
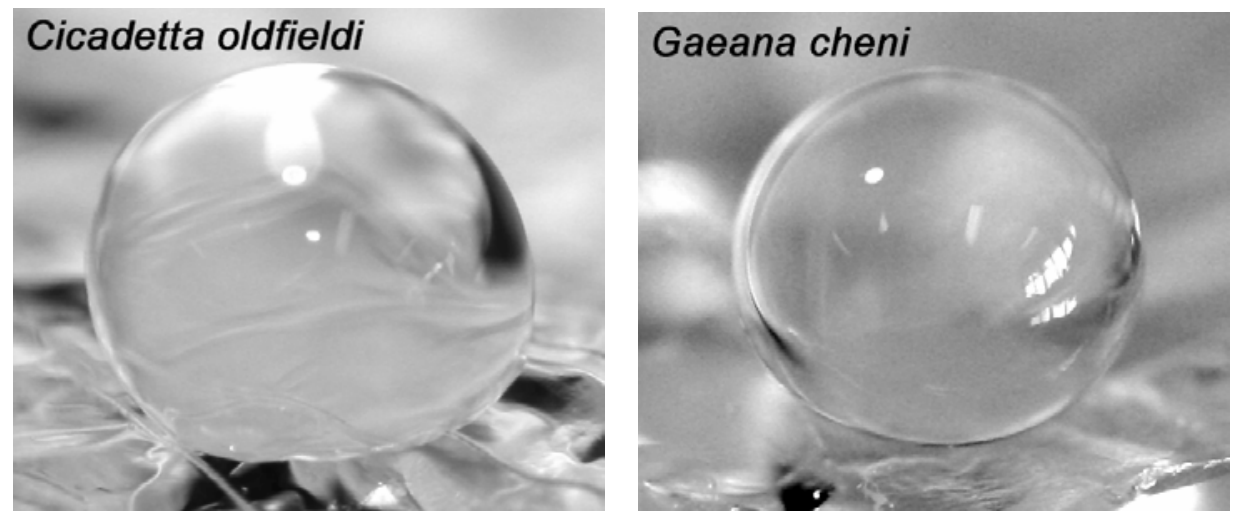
Figure $810 \mu$ water drops on PDMS replicas of Cicadetta oldfieldi, Gaeana cheni and Glenolean pulchellus (continued)

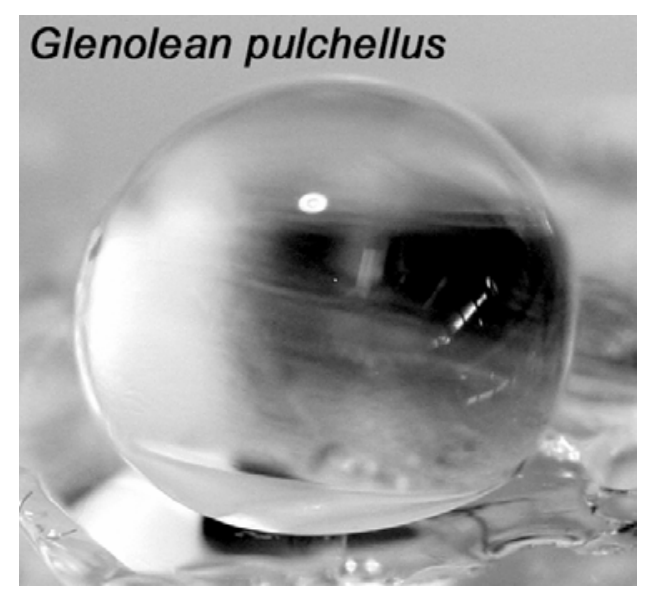

\subsection{Adhesion and friction}

The adhesion and friction properties have been measured on the selected insect species based on the hypothesis that contamination and wettability are related to insect habit and/or SA/BM values. Two different sized spherical bodies with hydrophilic chemistries have been used to measure adhesion and friction with the insect wing membranes [Figure 6(a) - left axis] using AFM. The dimensional differences are used to mimic contact conditions of particles, which would normally come into contact with the structured surfaces. Moreover, future fabricated materials based on natural nano/micro structures will interact with objects of these size-ranges.

A comparison with a hydrophilic silicon sample with a native oxide layer highlights the adhesional differences between the various surfaces. For the case where the silica sphere comes into contact with the silicon dioxide surface, meniscus forces at the point of contact between the tip/particle and the surface accounted for the high adhesive forces. The meniscus force between a sphere and a flat surface can be expressed as a function of CA and other parameters (Bhushan, 2002)

$$
F=2 \pi R \gamma(1+\cos \theta)
$$

where $R$ is the radius of the tip/particle and $\gamma$ the surface energy $\left(0.0728 \mathrm{~J} / \mathrm{m}^{2}\right.$ for water $)$ of the liquid film. The predicted force of adhesion for the hydrophilic AFM tip interacting with the hydrophilic silica surface is $8-20 \mathrm{nN}$ in reasonable agreement with the measured value of ca. $11 \mathrm{nN}$. The value calculated from equation (3) for the $31 \mu \mathrm{m}$ spheres yielded a much larger adhesive force than was experimentally determined (experimental value ca. $450 \mathrm{nN}$ ). The discrepancy can be explained due to the particles having surface roughness on the nm-scale as observed by AFM imaging. Contact with the flat surface is made via a number of contact points, i.e., a multi-asperity regime, each with radii of curvature in the nm-range. 
The adhesion between the silicon tip and microsphere with insect cuticles represents a high surface energy contaminant particle coming into contact with low energy hydrophobic micro/nanostructures/arrays. Particle adhesion on the insect cuticles was much lower in comparison with that for the flat hydrophilic surface. The low adhesion value is consistent with other studies on various materials and reflects the low surface energy of the surface (e.g., Watson et al., 2008). Adhesion was also measured for the $31 \mu \mathrm{m}$ sphere on a polytetrafluoroethylene (PTFE) surface (CA 108 ${ }^{\circ}$ ) with a measured value of $60 \mathrm{nN}$. Thus, the insect cuticle membranes represent lower surface energy materials than the PTFE for interaction of particles at this length scale. It is evident that the topography of the wing membranes results in minimal actual contact between the touching surfaces. Some insects may encounter long periods without rainfall and fogging conditions for self-cleaning of wing surfaces. Low adhesion may help in these cases to minimise contamination from foreign bodies.

The adhesion of contaminant particles coming into contact with the wing membrane surface of Psaltoda claripennis and Cicadetta oldfieldi showed ultra low adhesion forces as small as $2 \mathrm{nN}$ for AFM tip sized spherical bodies $(10-15 \mathrm{~nm})$ and less than $20 \mathrm{nN}$ for $31 \mu \mathrm{m}$ sized silica particles.

The adhesion on the dragonfly and planthopper's cuticles are similar and reflects the comparable surface topographies of the two insects. Adhesion curves on the moth surface with a silica sphere showed multiple releases during the retract section of the curve ( $>50 \%$ of force distance curves recorded). It seems plausible that this is the result of the scale having multiple releases under load.

Frictional forces were measured with a $31 \mu \mathrm{m}$ sphere at a loading force, which is the characteristic of the adhesional force between the two different body contacts i.e., $31 \mu \mathrm{m}$ sphere and cuticle combinations. The adhesional force was chosen as this best represents frictional behaviour under normal contact conditions. The frictional loading force ratios obtained on the insect cuticles were consistently lower than that of the flat silicon oxide surface, which had a low coefficient of friction of ca. 0.1 . The effective coefficients of friction (based on the frictional force at the adhesive force loading) were in the range of 0.01 to 0.10 . These values reflect the low lateral forces for dynamic friction and demonstrate that only low frictional forces are required to remove contaminants of this size from the cuticle membranes.

\section{Conclusions}

In this study, we have evaluated the characteristics of contacts between bodies at different length scales by measuring the strength of interaction between two particle sizes with selected natural nanostructures. The two size-ranges were used to ascertain the contact conditions of particles, which would normally come into contact with the structured surfaces. The unique topographical micro and nanostructures found on the insect surfaces demonstrate design characteristics and features for surfaces with low wettability, adhesion and friction. We have also demonstrated replication of these designs by using the membranes as natural templates. The diversity of the structure topographies demonstrates a range of architectures suitable for optimising surface properties and replication for man-made structures/applications. 


\section{Acknowledgements}

The authors would like to acknowledge financial support from a Griffith University grant (2105780 GUEG). Jolanta Watson was partially funded by the Griffith University Postdoctoral Research Fellowship Scheme.

\section{References}

Abdelsalam, M.E., Bartlett, P.N., Kelf, T. and Baumberg, J. (2005) 'Wetting of regularly structured gold surfaces', Langmuir, Vol. 21, pp.1753-1757.

Ando, Y. and Ino, J. (1998) 'Friction and pull-off forces on submicron-size asperities', Wear, Vol. 216, pp.115-122.

Bhushan, B. (2002) Introduction to Tribology, Wiley, New York.

Blossey, R. (2003) 'Self-cleaning surfaces - virtual realities', Nature Materials, Vol. 2, pp.301-306.

Burton, Z. and Bhushan, B. (2005) 'Hydrophobicity, adhesion and friction properties of nanopatterned polymers and scale dependence for micro- and nanoelectrochemical systems', Nano Letters, Vol. 5, pp.1607-1613.

Cassie, A.B.D. and Baxter, S. (1944) 'Wettability of porous surfaces', Transactions of the Faraday Society, Vol. 49, pp.546-551.

Cleveland, J.P., Manne, S., Bocek, D. and Hansma, P.K. (1993) 'A non-destructive method for determining the spring constant of cantilevers for scanning force microscopy', Review of Scientific Instruments, Vol. 64, pp.403-405.

Cong, Q., Chen, G-H., Fang, Y. and Ren, L-Q. (2004) 'Super-hydrophobic characteristics of butterfly wing surface', Journal of Bionic Engineering, Vol. 1, pp.249-255.

Gao, L. and McCarthy, T.J. (2007) 'How Wenzel and Cassie were wrong', Langmuir, Vol. 23, pp.3762-3765.

Gao, X. and Jiang, L. (2004) 'Biophysics: water-repellent legs of water striders', Nature, Vol. 432, p.36.

Gibson, C.T., Watson, G.S. and Myhra, S. (1997a) 'Scanning force microscopy - calibrative procedures for 'best practice', Scanning, Vol. 19, pp.564-581.

Gibson, C.T., Watson, G.S. and Myhra, S. (1997b) 'Lateral force microscopy: a quantitative approach', Wear, Vol. 213, pp.72-79.

Gorb, S.N., Kesel, A. and Berger, J. (2000) 'Microsculpture of the wing surface in Odonata: evidence for cuticular wax covering', Arthropod Structure \& Development, Vol. 29, pp.129-135.

Lehto, A., Kojola, H., Lövgren, T. and Lönnberg, H. (1999) World Patent 99/54730.

Martines, E., Seunarine, K., Morgan, H., Gadegaard, N., Wilkinson, C.D.W. and Riehle, O. (2005) 'Superhydrophobicity and superhydrophilicity of regular nanopatterns', Nano Letters, Vol. 5, pp.2097-2103.

Mastrangelo, C.H. (1997) 'Adhesion-related failure mechanisms in micromechanical devices', Tribology Letters, Vol. 3, pp.223-238.

Parker, A.R. and Lawrence, C.R. (2001) 'Water capture by a desert beetle', Nature, Vol. 414, pp.33-34.

Rolland, J.P., Va Dam, R.M., Schorzman, D.A., Quake, S.R. and DeSimone, J.M. (2004) 'Solvent-resistant photocurable 'liquid Teflon' for microfluidic device fabrication', Journal of the American Chemical Society, Vol. 126, pp.2322-2323.

Tong, J., Sun, J., Chen, D. and Zhang, S. (2005) 'Geometrical features and wettability of dung beetles and potential biomimetic engineering applications in tillage implements', Soil \& Tillage Research, Vol. 80, pp.1-12. 
Vincent, J.F.V. and Wegst, U.G.K. (2004) 'Design and mechanical properties of insect cuticle', Arthropod Structure \& Development, Vol. 33, pp.187-199.

Wagner, T., Neinhuis, C. and Barthlott, W. (1996) 'Wettability and contaminability of insect wings as a function of their surface sculptures', Acta Zoologica, Vol. 77, pp.213-223.

Watson, G.S. and Watson, J.A. (2004) 'Natural nano-structures on insects - possible functions of ordered arrays characterized by atomic force microscopy', Applied Surface Science, Vol. 235, pp.139-144.

Watson, G.S., Blach, J.A., Cahill, C., Nicolau, D.V., Pham, D.K., Wright, J. and Myhra, S. (2003) 'Poly(amino acids) at Si-oxide interfaces - bio-colloidal interactions, adhesion and 'conformation', Colloid \& Polymer Science, Vol. 282, pp.56-63.

Watson, G.S., Blach, J.A., Cahill, C., Nicolau, D.V., Pham, D.K., Wright, J. and Myhra, S. (2004) 'Interactions of poly(amino acids) in aqueous solution with charged model surfaces - analysis by colloidal probe', Biosensors \& Bioelectronics, Vol. 19, pp.1355-1362.

Watson, G.S., Myhra, S., Cribb, B.W. and Watson, J.A. (2007) 'Morphology, mechanical properties and manipulation of living cells: atomic force microscopy', in Ivanova, E.P. (Ed.): Nanoscale Structure and Properties of Microbial Cell Surfaces, pp.145-173, Nova Publishing, New York.

Watson, G.S., Myhra, S., Cribb, B.W. and Watson, J.A. (2008) 'Putative functions and functional efficiency of ordered cuticular nanoarrays on insect wings', Biophysical Journal, Vol. 94, pp.3352-3360.

Wenzel, R.N. (1936) 'Resistance of solid surfaces to wetting by water', Industrial Engineering Chemistry, Vol. 28, pp.988-994.

Wong, P.Y., Miaoulis, I.N., Tada, H. and Mann, S. (1997) 'Selective multilayer thin-film development in insects', ASME Fundamentals of Microscale Biothermal Phenomena, American Society of Mechanical Engineers, New York. 